\title{
Book Review Essay: Museums, Activism, and the Importance of Self-Reflection:
}

Amy K. Levin

\begin{abstract}
Apsel, Joyce, and Amy Sodaro (eds) Museums and Sites of Persuasion: Politics, Memory, and Human Rights, Abingdon: Routledge, 2020, hardback £120, paperback $£ 34.99$, ebook £31.49, pp.232
\end{abstract}

\author{
Chynoweth, Adele, Bernadette Lynch, Klaus Petersen, and Sarah Smed (eds) \\ Museums and Social Change: Challenging the Unhelpful Museum, Abingdon: \\ Routledge, 2021, hardback £120, paperback £34.99, ebook £31.49, pp.214
}

\section{Cole, Johnetta Betsch, and Laura L. Lott (eds) Diversity, Equity, Accessibility, and Inclusion in Museums, Lanham, MD: Rowman \& Littlefield, 2019, hardback £61.41, paperback £25.29, ebook £21.67, pp.182}

One of the great pleasures of reading about socially-conscious museums is that readers can learn about controversial histories while enjoying the creativity of current practitioners. During lockdown, such works add the possibility of virtual travel to distant sites. Yet the swelling numbers of publications on this topic has a downside as well. Many projects qualify as what Bernadette Lynch (2011) refers to as 'empowerment lite'. Efforts to instigate meaningful and lasting social change may be stymied due to governmental oppression, lacklustre institutional commitment, or other circumstances. Books on these institutions can also be tiresome and uninspiring when they are written by those engaged so closely in the projects described that they lack critical distance or awareness of duplicative efforts. The three edited collections under review are rewarding even though they exhibit some of these shortcomings.

Diversity, Equity, Accessibility, and Inclusion in Museums, edited by Johnetta Betsch Cole and Laura L. Lott, focuses on the USA. The first section reprints useful articles from important figures, such as Lonnie Bunch (founding director of the US National Museum of African American History and Culture and currently Secretary of the Smithsonian Institution), as well as new pieces. Its more general focus renders it a useful preparation for the other two books being reviewed. The older documents are more easily accessible in book form than behind paywalls for subscribers. Re-reading these documents reminds us of how little has changed in some areas: for instance, Lonnie Bunch suggests that museum employees as a group will only become more representative of the public at large if accrediting institutions make a diverse staff a requirement (7). In the newer sections of the book, the reader will find significant material on diversifying museum boards. Cinnamon Catlin-Legutko, whose leadership in diversifying institutions has been superior, stresses the importance of facilitated dialogues. She identifies aspects of racial bias training that are essential and should be non-negotiable. Elaine Heumann Gurian, as always, provides thoughtful insights, this time with a biographical essay on her own journey toward racial equity in museums. Eduardo Díaz's contribution on first voices is also informative, as is Haben Girma's examination of the benefits of universal design for everyone. Other articles cover populations that have often been excluded, such as LGBTQ+-identifying people and Native Americans. Some chapters are helpful; others reiterate what can be read elsewhere. An example of such duplication is an article about identifying internal bias within organizational structures. The appendices include the fascinating Andrew W. Mellon Foundation Art Museum Staff Demographic Survey; however, some of the charts are hard to interpret. 
Museums and Sites of Persuasion, edited by Joyce Apsel and Amy Sodaro, and Museums and Social Change: Challenging the Unhelpful Museum, edited by Adele Chynoweth, Bernadette Lynch, Klaus Petersen, and Sarah Smed, take a global scope, considering Asian, African, and/or Australian institutions. Apsel and Sodaro include memorial sites in addition to museums and address the constraints faced by state-sponsored institutions. The volume edited by Chynoweth et al. is especially valuable for its theorizing on 'helpful' solutions, although its focus is narrower.

Apsel and Sodaro's edited collection engages with important topics in the field today, such as memory and memorializing; storytelling; 'difficult' histories; human rights; empathy; performativity; activism; colonialism and decolonization; affective responses; and authenticity. Consequently, most readers will find something of interest. The theoretical introduction lays out these themes and addresses the problematics of shifting museum narratives toward an emphasis on freedom and human rights in nations with histories of violence, trauma, and repression. Distinguishing between institutions that deploy pathos (defined as 'the appeal to the audience's emotions' (9)), as opposed to logos ('the appeal to logic and reason' (9)), Apsel and Sodaro indicate that museums and memorials may succeed only in replacing one hegemonic narrative with another, and that deep affective impressions created in visitors raise ethical concerns. The remainder of the chapters present case studies of institutions in Africa, the USA, Asia, and Europe in order to illustrate and deepen these points. These contributions engage somewhat with broader theories on memory discourses and the authenticity of experience versus witnessing. Articles on certain institutions were fascinating - most notably, one on the changes to Kosovo's NEWBORN Monument and the memorial to the 1968 My Lai Massacre. The book's final section on 'resistance through memory' underscores the role of governmental regimes in deciding who is victor and who is victim, as well as the ways in which memorializing institutions may be governed by official state narratives. One cannot help wondering how all of these forces will come into play in future exhibitions on Myanmar history.

At the same time, the book would have been stronger with more sustained analysis. Theory drops out or is limited to often superficial references to the notions of logos and pathos developed in the introduction. Significant issues are neglected; for example, several articles allude to survivor trauma at memorial sites, but they do not address the question of how this trauma should be dealt with in any sustained manner. The emphasis on individual case studies also renders it difficult to focus on cross-cutting issues: do some rhetorical strategies appear across cultures? Do certain discursive or rhetorical approaches result in particular outcomes, for instance, a willingness among foreigners to fund a site?

Chynoweth et al.'s collection Museums and Social Change is in some ways the most helpful of the three texts. Among its strengths are its definition of a 'useful' museum (one that works with rather than for target audiences and sees them as full human beings rather than 'problem' populations exhibiting a lack or need). The institutions discussed take unusual approaches toward their constituencies, whether the latter are welfare recipients, care leavers, or women whose stories have been neglected. Also notable is the extent to which the authors of various chapters engage in self-reflection and criticism, assessing the successes and failures of their projects. Kathrin Pabst asks: 'Are we on the right track? If so, where on the track are we, taking the procedures and outcomes into consideration?' (123). Similarly, Parry et al. conclude their article by noting the benefits of collaborating with stakeholders, with the caveat that:

[T] his is unhelpful, however, if we fail to reflect on the potential harm caused in the process - by making assumptions about who should do these activities, or what they can contribute; by underestimating the range of approaches that can result in a successful outcome; and by expecting the process to be painless or problem-free (158).

Not only are keen self-critical perspectives refreshing, but they allow practitioners to move forward without repeating others' errors. The collaborations described within this book are most often ones that genuinely centre marginalized communities and show empathy. 'Useful' forms of activism are the topic of the concluding chapter, which focuses on how the Danish 
Welfare Museum supports care leavers in accessing and understanding their case records, promoting social good.

As with Aspel and Sodaro's collection, this text tends to be heavy on case studies, with theory largely dropping out as it proceeds. The individual chapters, while interesting, would be more useful if contributors had spoken in greater detail about the broader applicability of their work. Finally, the book is diminished by a central imbalance. Many, but not all, of the chapters focus on the Danish Welfare Museum. Other institutions are represented to a lesser extent. The content might have worked better had there been one volume on the Danish Welfare Museum, its unique position as well as its successes and failures. Another book could then have explored the ways in which other venues are helpful or unhelpful.

Clearly, all of these volumes make significant points, but they serve slightly different audiences, not only geographically, but also in terms of institution type. Diversity, Equity, Accessibility, and Inclusion in Museums centres on US museums and serves as a convenient reader that incorporates past and current viewpoints. It could be used in classrooms with students who lack a historical perspective. Museums and Sites of Persuasion is particularly valuable to those facing conflicting narratives of witnessing and memorialization, for instance museums dedicated to genocide or civil wars. It also offers assistance to those challenged by official or governmental constraints. Museums and Social Change offers consistent discussions of how to involve marginalized communities in exhibits about themselves. Here, the editors and contributors assume the institutions have latitude in the narratives they present.

All three books raise important questions about the role of theory in our field and the potential conflicts of interest inherent in writing about one's own projects. Academic scholarship is based on the notion of researchers presenting their new work; self-reflection, critical thinking, and a conviction of the productive possibilities stemming from being open about failure are equally essential. These strategies yield a stronger understanding of historical conflicts and set in relief research that is genuinely creative and unusual. Best of all, they allow us all to appreciate the many strengths of our field while refreshing our enthusiasm and passion for it.

Amy K Levin

Northern Illinois University

\section{References}

Lynch, B. (2011) Whose Cake is it Anyway: A Collaborative Investigation into Engagement and Participation in 12 Museums and Galleries in the UK, London: Paul Hamlyn Foundation, https://www.phf.org.uk/publications/whose-cake-anyway/. 